\title{
Functional availability studies of military vehicles in terms of operation intensity
}

\author{
Kamil PRZYBYSZ*1 \\ ${ }^{1}$ Military University of Aviation, Aeronautics Facultys
}

\begin{abstract}
Keeping vehicles technically suitable is strictly dependent on the intensity and nature of the damage. Determining the factors influencing functional availability comes down to investigating the causes of vehicle damage. Studies and analysis of the results have confirmed that functional availability for military vehicles can be estimated, taking into account vehicle intensity and reliability. The intensity of use may be taken into account by appropriate selection of layer tests, classified by intensity of use and by observing changes in functional availability with an increase in the number of trips, reflecting the intensity of use. Studies have found that the intensity of use in the range of average intensity of use of military vehicles does not significantly differentiate the level of availability.
\end{abstract}

Keywords: Functional availability, reliability, operation intensity, military vehicles.

\section{Introduction}

All combat and operational activities of the military require adequate logistical support, which is important for achieving the previously set goals. An important element of the military logistical support system is the technical subsystem, the key implementing element of which are military vehicles.

It was only during the actual tasks of technical support, during combat operations or during missions outside the country, that it was noted the improvement of the technical and tactical parameters of military vehicles (firepower, range, speed, resistance to enemy means of destruction) is not the only solution that ensures success in the implementation of assigned tasks. An important element, affecting the value of the probability of taking on and completing the assigned task successfully, is the level of functional availability of the military vehicle. It is characterized by the ability of the object to take action.

A fundamental problem in shaping the availability of modern military vehicles is the fact that technical progress, which perfectly ensures the improvement of these vehicle performance, does not proportionally increase their reliability and thus readiness. Modern technologies used in military vehicles are often more unreliable in terms of changing, specific conditions of use of military vehicles than older technological solutions that reduce performance but are more reliable.

This work provides a method for quantifying the functional availability of military vehicles in terms of reliability and intensity of operation.

\section{Effect of conditions and operating intensity on damage intensity}

The readiness of a technical facility to perform tasks directly depends on the intensity of the damage. Given the causes of damage, the forcing factors can be divided into three groups [1]:

- working (internal) factors operating during the use of the vehicle,

- external factors resulting from ambient conditions, operating independent of the operational condition of the vehicle (use, repair or downtime),

*Corresponding author: E-mail address: (k.przybysz@law.mil.pl) Kamil PRZYBYSZ 
- anthropotechnical factors resulting from human activities during use and servicing.

All the above mentioned groups of factors are interrelated, as described in previous studies [5, 6]

The nature of these factors is also extremely important for assessing readiness, with regard to the frequency of appearance and the duration of the loads. The classification of these loads according to the above criteria is given in Figure 1.

The duration and frequency of the internal and external forces described above depend to a great extent on the intensity of operation.

Intensity of use of the vehicle in literature $[1,2]$ is evaluated by means of a meter expressing the average value of the number of kilometers driven, or the amount of mass transported to a given distance in a given unit of time.

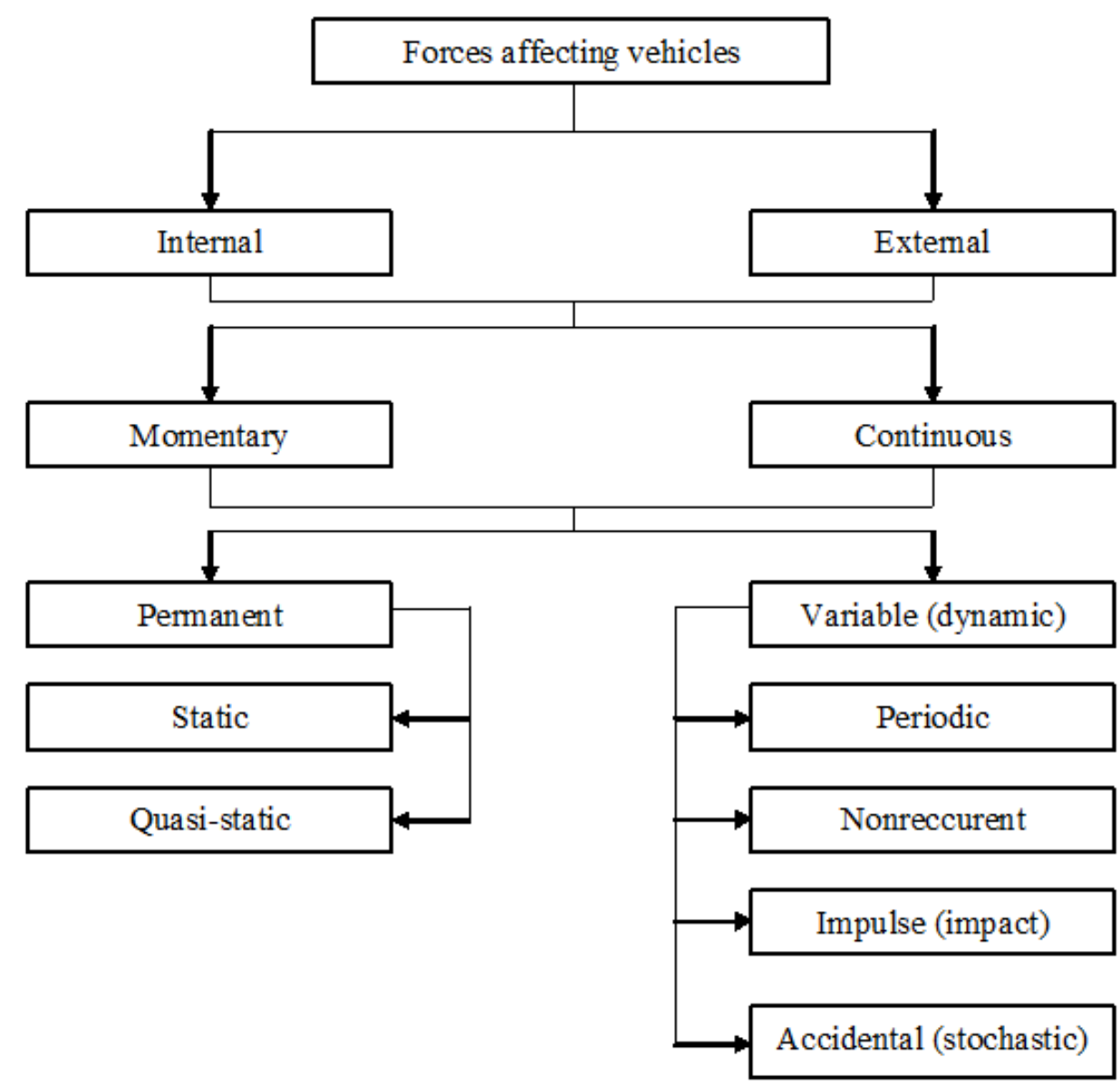

Figure 1. Classification of the forces (loads) of military motor vehicles [4]

The effect of the intensity of use of vehicles on the mileage between damage was presented at work (Kruk, 1991), where the author used the operational data of trucks of the selected brand, used on a daily basis in military units. In this case, the intensity of damage is expressed in the following formula [7]:

$$
q=\frac{1}{t_{2}-t_{1}} \sum_{i}^{n}={ }_{1} Q_{i}
$$

where:

$\mathrm{n}$ - the number of days the car worked, 
$t_{2}-t_{1}$ - the time interval during which the events are recorded: active use (vehicle operation) and passive (waiting for work),

$\mathrm{Q}_{i}$ - the operational potential (mileage) discharged during the i-th working day of the vehicle.

The effect of the intensity of use on vehicle readiness is presented in the publication [7] by expressing the stationary readiness indicator $\mathrm{Kg}$ by the mileage between damage and intensity of use:

$$
K_{g}=\frac{S_{u i}}{S_{u i}-T_{0} q_{i}}
$$

where:

$\mathrm{S}_{u} i$ - the average mileage between the damage, i-th of the car,

$\mathrm{T}_{0}$ - average duration of corrective service/car repair,

$\mathrm{q}_{i}$ - intensity of use i-th of the car.

Figure $2[3]$ shows the empirically determined characteristics of the course between damage - Su in mileage function $-\mathrm{s}$, for different intensity of use $-\mathrm{q}$ meeting the condition $\mathrm{q} 1<\mathrm{q} 2<\mathrm{q} 3<\mathrm{q} 4<\mathrm{q} 5$. The first q1 group is represented by vehicles that have worked an average of 16 days per year, the next q2 is vehicles with a usage intensity of 45 days per year, the next groups are increasing usage intensity of 60, 70 and more than 85 days per year respectively for the q5 vehicle group.

Analyzing the presented characteristics in Figure 2, it is easy to see that for a certain value of the mileage of the vehicle from the beginning of operation, the dispersion of mileage values between the damage - $\mathrm{S}_{u}$ is quite large, for the individual intensity of use $-\mathrm{q}$ and the differences in $\mathrm{S}_{u}$ values do not change significantly in the function of the mileage from the beginning of operation.

At work [7] it was noted that with low vehicle usage, the dominant factor causing damage is aging processes, which work while waiting for use. In the case of high intensity of use, damage is generated predominantly as a result of the influence of working processes during the operation of the vehicle, where the tribological processes predominate.

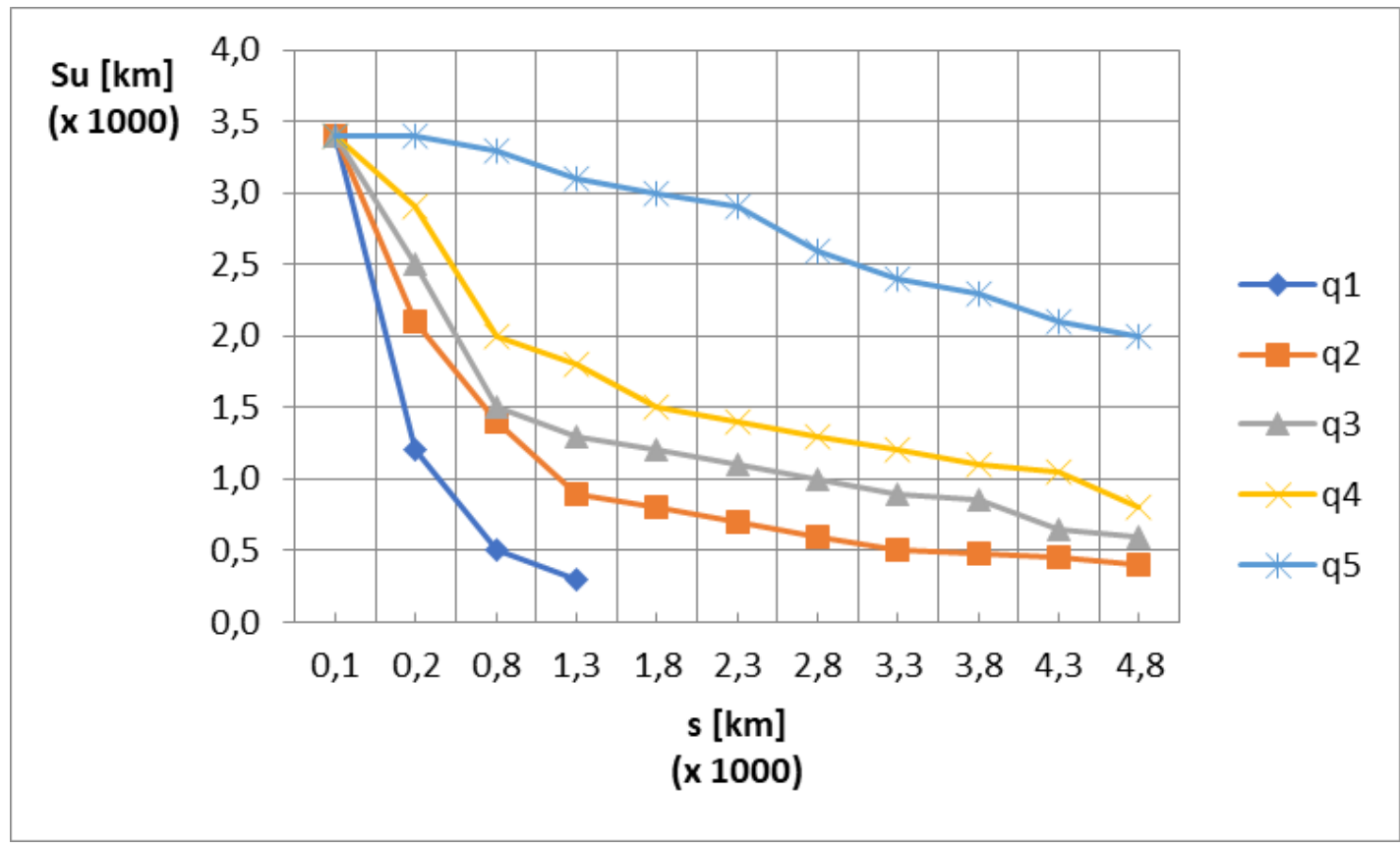

Figure 2. Example of characteristics $\mathrm{Su}=\mathrm{f}(\mathrm{s})[\mathrm{km}]$ for different $\mathrm{q}[\mathrm{km} /$ day $][3]$

The higher position of the characteristics in Figure 2 for higher intensity of use indicates that its downtime is more harmful to the vehicle than its use with average intensity. Unfortunately, this problem affects military vehicles, where most of the vehicles in use can be divided into two groups according to the intensity of use: 
- very intensively used vehicles, where the mileage between the damage is determined by the tribological processes and results from the cursory or untimely servicing, due to the high intensity of operation (vehicles for the carriage of passengers and the transport of cargo);

- vehicles with very low intensity of use, where the mileage between damage is due to ageing processes caused by prolonged, harmful environmental effects and negligence resulting from poorly carried out maintenance procedures (heavy combat equipment and heavy engineering machines of the operational group, equipment in storage, constituting a war stock and equipment of " $\mathrm{P}$ " time receivables subject to short-term or long-term maintenance, including non-part-time equipment).

\section{Own research}

The research was carried out to determine the effect of vehicle intensity on functional availability level. The main studies were carried out using four layered tests of military vehicles of different types and brands from the second phase of operation, with a varied mileage from the beginning of operation and an average mileage per year from 621 $\mathrm{km}$ to $22530 \mathrm{~km}$, classified according to the average intensity of use per year, determined during the four years of observation. The tests in question form the following quantities of vehicles with a corresponding average mileage of the year:

- first test: 10 military vehicles, average mileage per year of individual test vehicles from 621-1262 km (average mileage per year for test vehicle $891 \mathrm{~km}$ ),

- second test: 11 military vehicles, average mileage per year of individual test vehicles from 1820 to $5498 \mathrm{~km}$ (average mileage per year for test vehicle $3364 \mathrm{~km}$ ),

- third test: 9 military vehicles, average mileage per year of individual test vehicles from 6128-11 870 km (average mileage per year for the test vehicle $9527 \mathrm{~km}$ ),

- fourth test: 16 military vehicles, average mileage per year of individual test vehicles from $12718-22530 \mathrm{~km}$ (average mileage per year for the test vehicle $16912 \mathrm{~km}$ ).

The studies obtained average values of the stationary readiness indicator for each vehicle test, as shown in Table 1 .

Table 1. Basic measures of descriptive statistics indicator $\mathrm{K}_{g}$

\begin{tabular}{|c|c|c|c|c|c|c|}
\hline Test No. & Number of vehicles observed & Arithmetic mean & Min & Max & Median & Standard deviation \\
\hline 1 & 10 & 0.9685 & 0.881 & 0.992 & 0.980 & 0.0347 \\
\hline 2 & 11 & 0.9752 & 0.907 & 0.996 & 0.985 & 0.0256 \\
\hline 3 & 9 & 0.9832 & 0.972 & 0.991 & 0.986 & 0.0071 \\
\hline 4 & 16 & 0.9833 & 0.914 & 0.993 & 0.988 & 0.0189 \\
\hline
\end{tabular}

When verifying the mean values of the stationary readiness indicator $\mathrm{K}_{g}$ calculated for the above-described tests, it is easy to see that the above values are similar despite the fact that the individual tests were classified according to different intensity of use per year. In addition, the dispersion of the $\mathrm{K}_{g}$ values in the individual tests highlighted in Table 1 is also quite insignificant, which is a great picture of the standard deviation values.

When analyzing the value of the stationary readiness indicator $\mathrm{K}_{g}$ as a function of the number of trips, reflecting the intensity of use of the vehicle, it can be seen that the value of the above indicator increases with an increase in the number of trips, after which it is set at a certain level and only slightly changes despite the increase in the intensity of use, that is, increasing the number of trips, as shown in Figures 3, 4, 5, 6.

\section{Conclusion}

When assessing the mileage of the stationary readiness indicator - $\mathrm{Kg}$ for vehicles as a function of the number of trips, as shown in Figures 3, 4, 5, 6, it was noted that the value of the said indicator increases with an increase in the number of trips, which reflects the intensity of use. This phenomenon can be observed for all vehicle tests, i.e. 


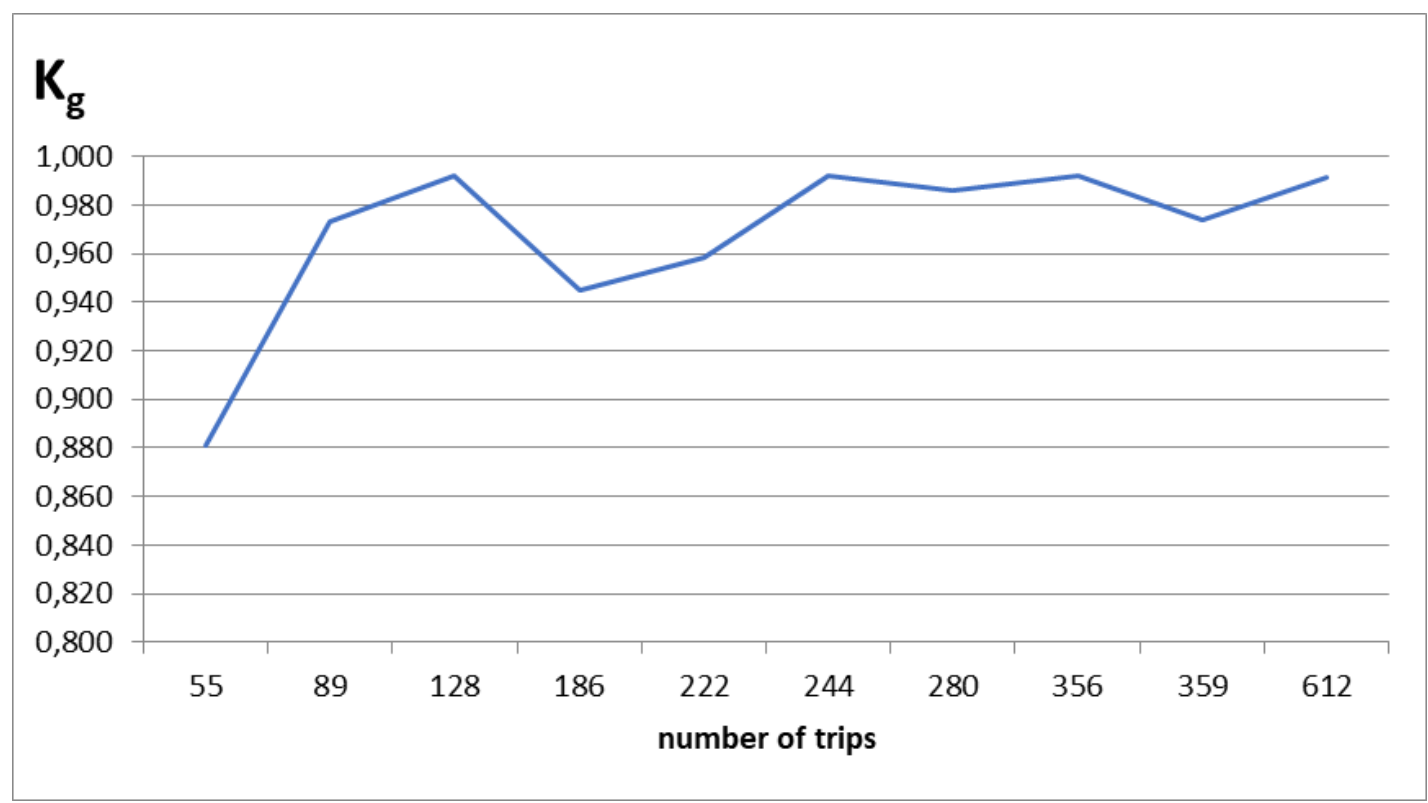

Figure 3. Running stationary readiness indicator $\mathrm{K}_{g}-$ the first test

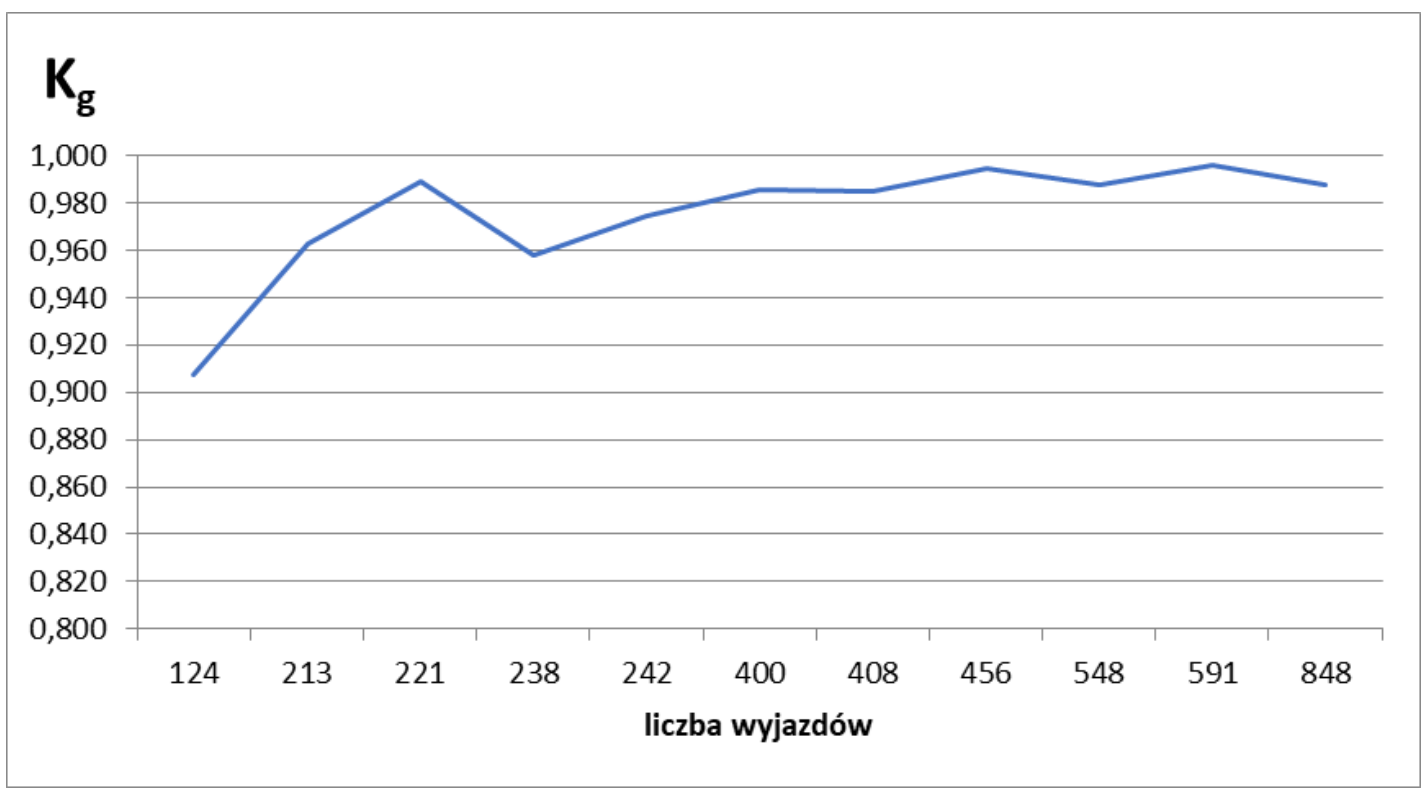

Figure 4. Running stationary readiness indicator $\mathrm{K}_{g}$ - the second test

at different values of average operating intensity. Contrary to expectations, the value of the mileage between the damage, which has a direct impact on the value of the stationary readiness indicator, does not decrease significantly with increasing the intensity of operation. An additional phenomenon that has a significant impact on the value of stationary readiness is the reduction of the average service life, repair with an increase in the intensity of operation. Military vehicles operated in units with greater intensity have similar repairs and maintenance performed in a shorter time, but more reliably.

The increase in stationary readiness indicator for all vehicle tests is observed to a certain level of the limit of the intensity of use, after which it begins to stabilize at a fixed level, after exceeding the limit number of departures, where the changes in the stationary readiness value are much smaller than in the initial part of the characteristics described above in Figures 3, 4, 5, 6. Only a very low or very high intensity of use causes a sharp increase in the number of repairs, which translates into a decrease in the value of the mileage between damage and a decrease in readiness.

When analyzing the functional availability of military vehicles, it is not possible to refer the calculated values to 


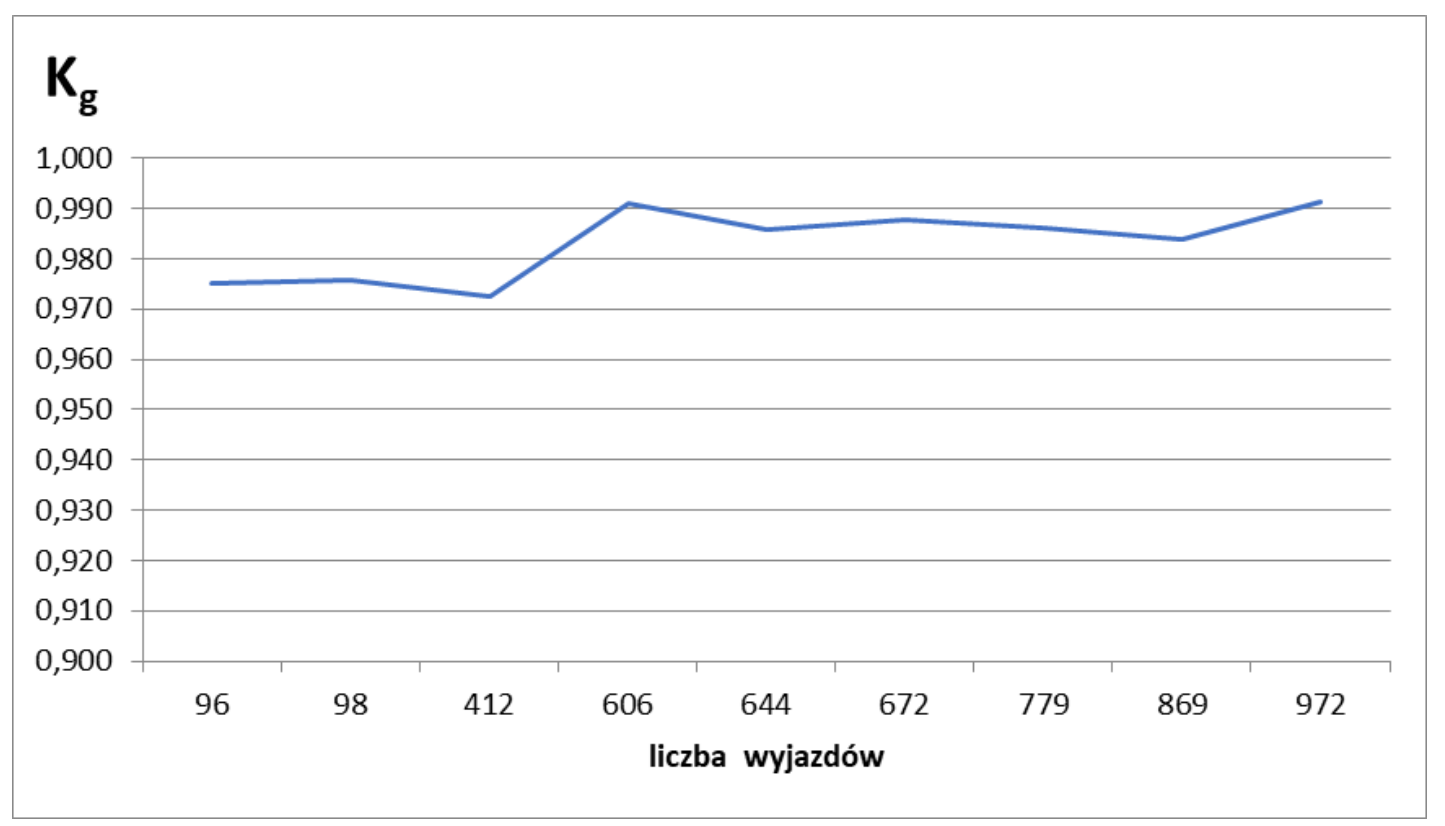

Figure 5. Running stationary readiness indicator $\mathrm{K}_{g}$ - the third test

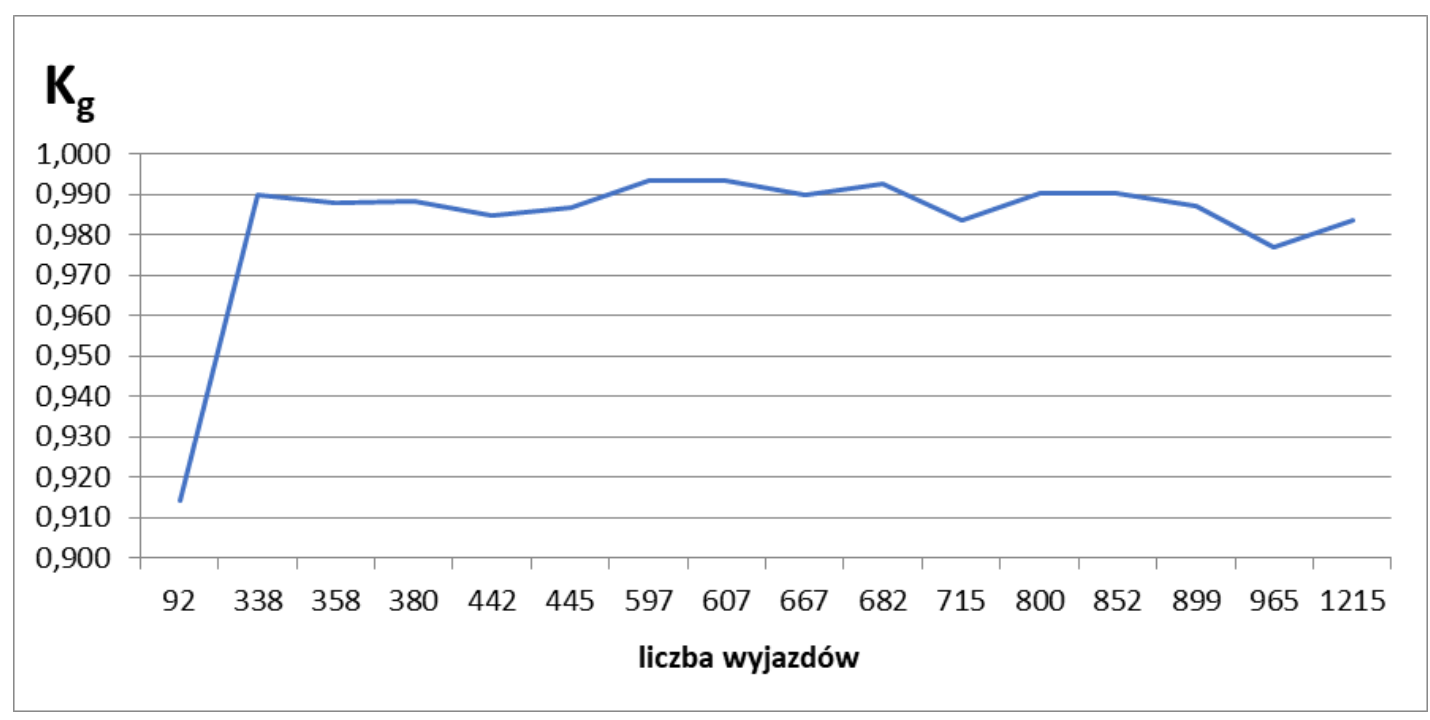

Figure 6. Running stationary readiness indicator $\mathrm{K}_{g}$ - the fourth test

civilian vehicles, e.g. buses of a civilian transport company. First of all, military vehicles have different operating characteristics, especially a much lower average intensity of use. The range of factors affecting a military vehicle in terms of readiness is much wider than for a civilian vehicle. Taking into account the results of the tests carried out, it should first of all be concluded that the vehicle is more harmful to its downtime than to use with an average intensity. This is perfectly confirmed and illustrated by the mileage of the stationary readiness indicator as a function of the number of all trips made for all tested vehicle tests, as shown in Figures 3, 4, 5, 6.

\section{References}

1. Hebda, M. \& Janicki, D. Trwałość i niezawodność samochodów w eksploatacji, Warszawa: Wydawnictwa Komunikacji i Łączności. (1977).

2. Hebda, M. \& Mazur, T. Podstawy eksploatacji pojazdów samochodowych, Warszawa: Wydawnictwa Komunikacji i Łączności. (1984). 
3. Kruk, Z. Badania efektywności systemu eksploatacji pojazdów kołowych na podstawie oceny gotowości technicznej wytypowanych marek pojazdów użytkowanych w wojsku, Archiwum WITPiS 1990/91 1990.

4. Niziński, S. et al. Diagnostyczne wojskowych pojazdów mechanicznych, Sulejówek-Radom. (2011).

5. Przybysz, K. Dependability for the military vehicles in the safety aspects. Safety engineering of anthropogenic objects 1 (2020).

6. Przybysz, K., Dygnatowski, S. \& Grzesik, N. An analysis of reliability of military vehicles. Journal of KONBiN 49 (3 2019).

7. Simiński, P. et al. Rozwój środków transportu w SZRP, BEL Studio Sp. z. o. o. (ed Simimiński, P.) Warszawa, 2013. 